\title{
Quality of Life and Treatment Outcome of Psychiatric Morbidities in Cancer Patients
}

\author{
Prashwas Thapa ${ }^{l}$, Namrata Rawal ${ }^{1}$, Yadav Bistal. \\ ${ }^{1}$ Department of Neuropsychiatry, Shree Birendra Hospital, Kathmandu, Nepal.
}

\begin{abstract}
Introduction: Cancer is associated with significant psychosocial morbidity and has impact on quality of life. An appropriate psychiatric management of cancer patient may improve the ultimate quality of living. The objective of this study was to see the outcome of treatment of depression and anxiety and its effect in quality of life in cancer patients.

Methods: The objective of this study was to see the outcome of treatment of depression and anxiety and its effect in quality of life in cancer patients. A cross sectional study was used. A total of eighteen (18) cancer patients with depression, anxiety; and both depression and anxiety were assessed for quality of life and provided treatment. The tools used were General Health Questionnaire (GHQ), Hospital Anxiety and Depression Scale (HADS) and World Health Organization Quality of Life (WHOQOL) scale.

Results: The study concluded that $43.75 \%$ of depressed and $41.66 \%$ of anxiety cancer patients improved on treatment and there also was a significant improvement in quality of life, specially in psychological and physical domain.

Conclusions: Oncology centres should work in close liaison with psychiatrists which can improve the quality of life of cancer patients.
\end{abstract}

Keywords: anxiety; cancer; depression; GHQ; HADS; WHO QOL.

\section{INTRODUCTION}

Many researchers have reported that six mental disorders occur more frequently in cancer patients to warrant a detailed assessment and clinical intervention. Three represent direct reaction to illness: adjustment disorders with depression and/or anxiety, major depression and delirium. Others (primarily anxiety disorders, personality disorders and major depressive disorders) are pre-existing conditions often exacerbated by the illness ${ }^{1,2}$.

Various studies over the years have shown that treatment outcome of psychiatric morbidities in cancer patients have an excellent outcome. In noncontrolled studies of depressed cancer patients, response rates of 73 to $100 \%$ have been attained ${ }^{3}$. In a study of 146 patients with cancer referred to a liaison psychiatry service, antidepressants were prescribed for $67 \%$ of patients with $80 \%$ showing good clinical response to treatment with few side effects 4 .

Valente SM (1997) also quote that an approximate 80 $-90 \%$ of depressed patients are effectively treated with psychotherapy, and/or pharmacological or somatic interventions ${ }^{5}$.

A recent Indian study identified $44 \%$ cancer patients as probable psychiatric cases on the basis of GHQ 12 (Cutoff $>2$ ) and this number had significantly reduced to $12(24 \%)$ after psychiatric treatment. On the Carroll Rating Scale for Depression a cut-off of $b>10$ had identified $78 \%$ patients as depressed prior to treatment. After psychiatric treatment, this fell to $42 \%{ }^{6}$.

This cross sectional study was designed to assess the outcome of treatment of anxiety and depression in cancer patients and its effect in their quality of life.

\section{Correspondence:}

Dr. Prashwas Thapa,

Dept. of Neuropsychiatry, Shree Birendra Hospital

Kathmandu, Nepal.

Email: prashwas_thapa@yahoo.com 


\section{METHODS}

This cross sectional study was carried out from $24^{\text {th }} \mathrm{Feb}$ 2012 for duration of six weeks, on cancer patients with psychiatric morbidity at Shree Birendra Hospital.The interviewer introduced himself as a doctor conducting a study of psychiatric morbidities in cancer patients. All the subjects in the study were explained the nature and importance of the study and informed consent was obtained from each for the study and as well as for the treatment. The cases include army personnel and their dependants, irrespective of cancer types, either as a freshly diagnosed case or known cases for surgery or follow up cycles of chemotherapy or radiotherapy. Those who were severely or terminally ill or patients undergoing treatment at ICU and patients suffering from other concomitant illnesses were excluded from this study.

Eighteen cancer patients, observed to have possible psychiatric co-morbidity, were enrolled in this study and random sampling was done.

All the eighteen patients were administered the following psychological tests:

\section{A. GHQ (General Health Questionnaire):}

GHQ is a screening instrument developed to assess the extent of non-psychotic psychiatric illness and current mental well being for the past few weeks ${ }^{7}$. It is extensively used in both community settings and general practice. This scale has been extensively validated over cultures, languages, age groups (except extremes of ages), gender and education with very high sensitivity and specificity. GHQ 12 was used in present study. Scoring was done by using binary method with 2 as cut off score.

\section{B. Hospital anxiety and depression scale (HADS):}

The HADS is a self-report questionnaire developed to detect adverse anxiety and depressive states ${ }^{8}$. Since it was developed for use in non-psychiatric departments, it does not rely upon symptoms that may be present in people with physical illness alone, such as pain and weight loss. It has 14 items, 7 related to anxiety and 7 to depression. Scoring is from 0-3 and score ranges from 0-56. The norms give an idea of the level of anxiety and depression ( $0-7=$ normal, 8-10=mild, $11-14=$ moderate and $15-21=$ severe).In the present study, HADS has been used to assess anxiety and depression in cancer patients.

\section{WHO QOL BREF Scale:}

The WHO QOLBREF assessments are made under four domains : 1) physical health domain, 2) psychological health domain, 3) social relationship domain. 4) environmental domain. The normal physical health domain scores range from $7-35$; for psychological health domain, it ranges from $6-30$. The normal social relationship domain scores range from $3-15$ and for environmental domain, it ranges from $8-40$. Higher scores indicate better quality of life.

Probable psychiatric morbidity was screened by using the General Health Questionare (GHQ) with a cutoff of $>2$ for cancer patients. Both anxiety and depression was assessed by using the Hospital anxiety and depression scale (HADS) taking a cutoff of $>7$. Quality of Life (on all 4 domains) was assessed by using the WHO QOL Scale.

Treatment was given for a period of 4 to 6 weeks only to those cancer patients scoring above 7 on the HADS scale for a period of 4 to 6 weeks. They were followed up regularly and a final follow up was done after 4 to 6 weeks of the initial evaluation where all the cancer patients, who had psychiatric morbidity, were reassessed with structured proforma and all the test materials to find out the response to treatment.

Frequency data were compared by using the 'chi' square test. For comparing the scores of psychological tests nonparametric tests were used.Wilcoxon test was used for comparing scores (of pretreatment and post treatment group) on psychiatric rating scales. The differences were considered significant if the ' $p$ ' value was less than 0.05. Statistical analysis was done in computer package.

\section{RESULTS}

All eighteen cancer patients had an GHQ score of more than 2 thus having a probable non psychotic psychiatric illness. The mean GHQ scores of cancer patients prior to treatment was $6.67(\mathrm{SD}=3.0293)$ and post treatment the score reduced to 4.67 (SD =3.124) (Table 8). Nine $(50 \%)$ out of eighteen patients who received treatment improved (Table 1). The mean anxiety score was $10(\mathrm{SD}=1.7889)$ before treatment and 7.81 ( $\mathrm{SD}=2.167)$ post treatment (Table 8). The distibution of anxiety scores before and after treatment is given in Table 2. Of the patients who received treatment for anxiety, seven (43.75\%) improved as per HADS cutoff of $<7$.The difference was statistically significant $(\mathrm{p}=<0.05)$ (Table 2). The mean depression score was $12.33(\mathrm{SD}=2.38)$ before treatment and 9.16 $(\mathrm{SD}=2.44)$ following treatment. The difference was statistically significant (Wilcoxon test; $\mathrm{p}=0.002$; Table $8)$. The distribution of depression scores before and after treatment is shown in Table 3. 
Of the patients who received treatment for depression, five $(41.66 \%)$ improved as per HADS cutoff of $<7$. But it was not statistically significant ( $\mathrm{p}=0.181$; Table 3 ), though there was statistically significant overall reduction in scores (Wilcoxon test; $\mathrm{p}=0.002$; Table 8). The mean physical health domain score was 18.89 $(\mathrm{SD}=7)$ before treatment and following treatment it was $21.39(\mathrm{SD}=5.97)$ The difference was statistically significant (Wilcoxon test; $\mathrm{p}=0.001$; Table 8 ). The distribution of physical health domain scores before and after treatment is shown in Table 4.

The mean psychological domain score was 16.67 $(\mathrm{SD}=4.15)$ before treatment and $18.89(\mathrm{SD}=3.06)$ following treatment. The difference was statistically significant (Wilcoxon test; $\mathrm{p}=0.002$; Table 8 ). The distribution of psychological domain scores before and after treatment is shown in Table 5. The mean social relationship domain score was $9.88(\mathrm{SD}=2.08)$ before treatment and $10.11(\mathrm{SD}=2.42)$ after treatment. The difference was not statistically significant (Wilcoxon test; $\mathrm{p}=0.180$; Table 8 ). The distribution of social relationship domain scores before and after treatment is shown in Table 6. The mean environmental domain score was $25.16(\mathrm{SD}=3.65)$ before treatment and 25.33 $(\mathrm{SD}=3.58)$ following treatment. The difference was not statistically significant (Wilcoxon test; $\mathrm{p}=0.083$; Table 8). The distribution of environmental domain scores before and after treatment is shown in Table 7.

Table 1: Comparision of GHQ scores in cancer patients.

\begin{tabular}{|l|c|c|}
\hline \multicolumn{1}{|c|}{ GHQ SCORE } & PRETREATMENT GROUP & POST TREATMENT GROUP \\
\hline 0 & 00 & 00 \\
\hline $1-2$ & 00 & 09 \\
\hline$>2$ & 18 & 09 \\
\hline
\end{tabular}

Table 2: Comparision of anxiety score (HADS) in cancer patients

\begin{tabular}{|c|c|c|c|}
\hline ANXIETY SCORE & $\begin{array}{c}\text { PRETREATMENT } \\
\text { GROUP }\end{array}$ & $\begin{array}{c}\text { POST TREATMENT } \\
\text { GROUP }\end{array}$ & $<$ \\
\hline $0-7$ (No Anxiety) & 02 & 09 & $<0.05$ \\
\hline $8-10$ (Mild) & 10 & 06 & \\
\hline $11-14$ (Moderate) & 06 & 03 & \\
\hline $15-21$ (Severe) & 00 & 00 & \\
\hline
\end{tabular}

Table 3: Comparision of depression score (HADS) in cancer

\begin{tabular}{|l|c|c|c|}
\hline Depression Score & Pretreatment Group & Post Treatment Group & $\mathrm{p}$ \\
\hline $0-7$ (No Depression) & 06 & 11 & 0.181 \\
\hline $8-10$ (Mild) & 02 & 02 \\
\hline $11-14$ (Moderate) & 08 & 05 \\
\hline $15-21$ (Severe) & 02 & 00 & \\
\hline
\end{tabular}

Table 4: Comparision of WHO QOL (Physical health domain score) in cancer patients before and after treatment

\begin{tabular}{|c|c|c|}
\hline PHYSICAL HEALTH DOMAIN SCORE & $\begin{array}{c}\text { PRETREATMENT } \\
\text { GROUP }\end{array}$ & $\begin{array}{c}\text { POST TREATMENT } \\
\text { GROUP }\end{array}$ \\
\hline $7-10$ & 02 & 00 \\
\hline $11-15$ & 04 & 04 \\
\hline
\end{tabular}


MJSBH July-December 2013|Vol 12| Issue 2

\begin{tabular}{|l|l|l|}
\hline $16-20$ & 04 & 06 \\
\hline $21-25$ & 06 & 04 \\
\hline $26-30$ & 00 & 02 \\
\hline $31-35$ & 02 & 02 \\
\hline
\end{tabular}

Table 5: Comparision of WHO QOL (psychological domain score) in cancer patients before and after treatment

\begin{tabular}{|c|c|c|}
\hline PSYCHOLOGICAL DOMAIN SCORE & $\begin{array}{c}\text { PRETREATMENT } \\
\text { GROUP }\end{array}$ & $\begin{array}{c}\text { POST TREATMENT } \\
\text { GROUP }\end{array}$ \\
\hline $6-10$ & 00 & 00 \\
\hline $11-15$ & 06 & 02 \\
\hline $16-20$ & 08 & 10 \\
\hline $20-25$ & 04 & 06 \\
\hline $26-30$ & 00 & 00 \\
\hline
\end{tabular}

Table 6: Comparision of WHO QOL (social relationship domain score) in cancer patients before and after treatment

\begin{tabular}{|c|c|c|}
\hline SOCIAL RELATIONSHIP DOMAIN SCORE & $\begin{array}{c}\text { PRETREATMENT } \\
\text { GROUP }\end{array}$ & $\begin{array}{c}\text { POST TREATMENT } \\
\text { GROUP }\end{array}$ \\
\hline $3-5$ & 00 & 00 \\
\hline $6-10$ & 10 & 10 \\
\hline $11-15$ & 08 & 08 \\
\hline
\end{tabular}

Table 7: Comparision of WHO QOL (environmental domain score) in cancer patients before and after treatment

\begin{tabular}{|c|c|c|}
\hline ENVIRONMENTAL DOMAIN SCORE & $\begin{array}{c}\text { PRETREATMENT } \\
\text { GROUP }\end{array}$ & $\begin{array}{c}\text { POST TREATMENT } \\
\text { GROUP }\end{array}$ \\
\hline $8-10$ & 00 & 00 \\
\hline $11-15$ & 00 & 00 \\
\hline $16-20$ & 02 & 02 \\
\hline $21-25$ & 06 & 06 \\
\hline $26-30$ & 10 & 10 \\
\hline $31-35$ & 00 & 00 \\
\hline $36-40$ & 00 & 00 \\
\hline
\end{tabular}


Table 8: Psychological test results of cancer patients with psychiatric morbidity who received treatment (Wilcoxon test)

\begin{tabular}{|l|c|c|c|}
\multicolumn{1}{|c|}{ Test } & $\begin{array}{c}\text { Mean score prior to } \\
\text { treatment with } \\
\text { (Standard deviation) }\end{array}$ & $\begin{array}{c}\text { Mean score following } \\
\text { treatment with } \\
\text { (Standard deviation) }\end{array}$ & $\mathrm{p}$ \\
\hline GHQ & $6.67(\mathrm{SD}=3.0293)$ & $4.67(\mathrm{SD}=3.124)$ & 0.001 \\
\hline ANXIETY & $10(\mathrm{SD}=1.7889)$ & $7.81(\mathrm{SD}=2.167)$ & 0.001 \\
\hline DEPRESSION & $12.33(\mathrm{SD}=2.38)$ & $9.16(\mathrm{SD}=2.44)$ & 0.002 \\
\hline WHO QOL & $18.89(\mathrm{SD}=7)$ & & 0.001 \\
\hline 1.Physical & $16.67(\mathrm{SD}=4.15)$ & $18.89(\mathrm{SD}=3.06)$ & 0.002 \\
\hline 2.Psychological & 9.88 & $10.11(\mathrm{SD}=2.42)$ & 0.180 \\
\hline 3.Social Relationship & $(\mathrm{SD}=2.08)$ & $25.33(\mathrm{SD}=3.58)$ & 0.083 \\
\hline 4.Environmental & $25.16(\mathrm{SD}=3.65)$ & & \\
\hline
\end{tabular}

\section{DISCUSSION}

In the current study, treatment was given to only eighteen patients; ten had both anxiety and depression, two had only depression and six had only anxiety.

The mean GHQ scores of cancer patients prior to treatment was $6.67(\mathrm{SD}=3.0293)$ and post treatment the score reduced to $4.67(\mathrm{SD}=3.124)$. Post treatment 9 $(50 \%)$ patients scored $<2$ showing that $50 \%$ of patients who received treatment improved as per GHQ cut off below 2 (Table 1) but there was an overall decrease in GHQ scores and it was statistically significant (Wilcoxon test; $p=0.001$; Table 8). GHQ score distribution is shown in Table 1.

The anxiety score of 18 patients, who received treatment, had a mean score of $10(\mathrm{SD}=1.7889)$, which reduced to a mean score of $7.81(\mathrm{SD}=2.167)$ post treatment (Table 8 ). Seven $(43.75 \%)$ patients improved following treatment, as per HADS cut off of below 7. This was statistically significant $(p=<0.05$; Table 2). The anxiety score distribution is shown in Table 2. All seven patients who improved were of the mild anxiety group; however, there was overall reduction of scores of other patients as well but did not reach 7 or below (Wilcoxon test, $\mathrm{p}=0.001$; Table 2).

The depression score of 18 patients, who received treatment, had a mean score of $12.33(\mathrm{SD}=2.38)$ which reduced to $9.16 \quad(\mathrm{SD}=2.44)$ following treatment (Table 8$)$. Five $(41.66 \%)$ patients showed improvement following treatment as per HADS cut- off of below 7. This was not statistically significant $(p=0.181$; Table 31$)$. This may be due to the fact that patients were given short term treatment for a period of 4 to 6 weeks. But there was overall decrease in depression scores following treatment which was statistically significant (Wilcoxon test, $p=0.002$, Table 28). Of the five patients who improved, as per cut-off of $<7,2$ were mildly depressed and 3 were moderately depressed. There was reduction in score of the severely depressed patients as well but it did not reach 7 or below after treatment. The depression score distribution is presented in Table 3.

The WHO QOL (physical domain score) ranged from 9 to 32 with a mean of $18.89(\mathrm{SD}=7)$ before treatment and following treatment this ranged from 11-34 with a mean of $21.39(\mathrm{SD}=5.97)$. There was overall increase in QOL (physical domain score) which was statistically significant (Wilcoxon test; Table 28; $\mathrm{p}=0.001$ ). The distribution of WHO QOL (physical domain score) is presented in Table 4.

The WHO QOL (psychological domain score) ranged from 11 to 23 with a mean of $16.67(\mathrm{SD}=4.15)$ before treatment. This ranged from 14 to 24 with a mean of $18.89(\mathrm{SD}=3.06)$ following treatment. There was overall increase in WHO QOL (psychological domain score) following treatment and it was statistically significant (Wilcoxon test; $\mathrm{p}=0.002$; Table 8 ). The distribution of WHO QOL (psychological domain score) is presented in Table 5. 
The WHO QOL (social relationship domain score) ranged from 7 to 13 with a mean of $9.88(\mathrm{SD}=2.08)$ before treatment. This ranged from 7 to 15 following treatment with a mean of $10.11(\mathrm{SD}=2.42)$. Though there was overall increase in WHO QOL (social relationship domain score) following treatment, it was not statistically significant (Wilcoxon test; $\mathrm{p}=0.180$; Table 8). The distribution of WHO QOL (social relationship domain score) is presented in Table 6.

The WHO QOL (environmental domain score) ranged from 19 to 30 for cancer patients with psychiatric morbidity both before and after treatment, with a mean of $25.16(\mathrm{SD}=3.65)$ and $25.33(\mathrm{SD}=3.58)$ respectively. Though there was improvement in quality of life in this domain, it was not statistically significant (Wilcoxon test; $\mathrm{p}=0.083$; Table 28). The distribution of WHO QOL (environmental domain score) is presented in Table 7.

The response to treatment was $50 \%$ as assessed by GHQ following treatment of psychiatric morbidity (Table 1). The response to treatment for depression was (41.66\%) (Table 2) and for anxiety was (43.75\%) (Table 3) based on cut off of $<7$ but there was overall decrease in scores (Table $8)$. The study was not in agreement with other studies viz: Chaturvedi et al $(1994)^{4}-80 \%$, Valente SM et al $(1997)^{5}-80-90 \%$ of depressed patients, Fernandes et al (1987) - 77\%, ${ }^{9}$ Olin and Masard $(1996)^{10}-80 \%$, Natenshon $(1956)^{11}-96.1 \%$. The discrepancy may be due to the fact that all the patients in this study were treated for a very short time (4-6 weeks). The choice of psychotropic drugs also is considered another factor resulting in variation of response as medicines prescribed varied across other studies and the present study. Natenshon $(1956)^{11}$ had treated patients for upto 26 weeks with methyl phenidate which might have resulted in such a high response (96.1\%). All 3 studies by Fernandes et al (1987) ${ }^{9}$, Olin and Masand (1996) ${ }^{10}$ and Natenshon (1956) ${ }^{11}$ had used psycho stimulants whereas none of our patients were treated with psycho stimulants. The other reason for low response rate may be due to the fact that most of our patients were admitted for cycles of radiotherapy and chemotherapy. Studies have shown that there is duplication of depressive symptoms during course of chemotherapy and severe depression is noted to increase from $0-17 \%$ during such period ${ }^{12}$. Radiotherapy also tends to increase risk of depression via fatigue syndrome and this may also have resulted in low response rate as compared to other studies ${ }^{13,14}$.

There was overall improvement in quality of life in all four domains following treatment, but was statistically significant in case of first two domains (Table 8). This was consistent with finding as per study conducted by Pathak et al $(2000)^{15}$.

Possible limitation of this study could be small and random sample size. Patients were provided treatment for a limited period of time (4-6 weeks) as against a minimum period of six months which are given to patients with primary depression and anxiety.

\section{CONCLUSIONS}

Present study shows that treatment leads to reduction in psychopathology and improvement in quality of life. Oncology centres and institutions working in close liaison with psychiatrists can significantly reduce the psychopathology of cancer patients as well as improve their quality of life.

\section{REFERENCES}

1. Iqbal A, Syed GMS and Siddiqui KS. Mental disorders in cancer patients: observations at a tertiary care center in Pakistan. Pak J. Med Sci 2002; 18(2): 109-16.

2. Rouhami M and Holland JC. Psychiatric aspects of cancer. In: Gelder MG, Lopez-Ibor JJ, Andreason N, editors. New Oxford Textbook of Psychiatry. 1st ed. New York: Oxford University Press, 2000; 1178-84.

3. Lovely MP. Quality of life in brain tumor patients. Semi Oncol Nurs. 1998; 14: 73-80.

4. Chaturvedi S, Maguire P, Hopwood P. Antidepressant medications in cancer patients. Psycho Oncology. 1994; 3: 57-60.

5. Valente SM, Saunders JM. Diagnosis and treatment of major depression among people with cancer. Cancer Nurs. 1997; 20(3): 168-77.

6. Ashraf S, Gupta AK, Choudhury S, Sudarsanan S et al. Effect of short term psychiatric intervention in cancer patients. Med J Armed Forces India. 2004; 60: 109-12.

7. Goldberg. The detection of psychiatric illness by questionnaire. Maudslay Monograph No 2. London: Oxford University Press, 1972.

8. Zigmond AS, Snaith RP. The hospital anxiety and depression scale. Acta Psychiatr Scand. 1983; 67: 361-70.

9. Fernandez F, Adams F. Methylphenidate treatment with head and neck cancer. Head and Neck. 1986, 
$8: 296-300$.

10. Olin J, Masand P. Psychostimulants for depression in hospitalized cancer patients. Psychosomatics. 1996; 37: 57-62.

11. Natenshon AL. Clinical evaluation of Ritalin. Dis Nerv System. 1956; 17: 392-6.

12. Zeigler G, Muller F. Prevalence and etiology of mental problems in tumor patients. Onkologie. 1986; 9(1): 18-26.

13. Fallowfield LJ, Baum M, Maguire GP. Effects of breast conservation on psychological morbidity associated with diagnosis and treatment of early breast cancer. British Med Journal. 1986; 293: 1331-4.

14. Maunsell E, Brisson J, Deschena L. Psychological distress after initial treatment for breast cancer. A comparison of partial and total mastectomy. Journal of Clinical Epidemiology. 1989; 42: 76571.

15. Pathak M, Sharma MP, Chaturvedi SK et al. Quality of life in patients with brain tumors. NIMHANS Journal. 2000; 18 (3 and 4): 197-203. 